\title{
Estimation of energy dissipation in step-pool reaches of mountain river - a field investigation
}

\author{
Abbas Torabizadeh ${ }^{1}$, Hamid-Reza Ghafouri ${ }^{1}$, Mohamadreza Majdzadehtabatabai ${ }^{2}$, and \\ Ahmad Tahershamsi ${ }^{3}$ \\ ${ }^{1}$ Shahid Chamran University of Ahvaz \\ ${ }^{2}$ Shahid Beheshti University \\ ${ }^{3}$ Amirkabir University of Technology Department of Civil and Environmental Engineering
}

November 23, 2021

\begin{abstract}
The bed of the step-pool rivers is adapted to the flow conditions in terms of the topographic position and the steep slope of the path in such a way to dissipate the water energy, along the river. The beds of these rivers is sinusoidal like the meander rivers. However, as the river banks are mostly rocky in mountainous areas and the erosion in these areas is less, the bed fluctuation of these reaches is mainly vertical. When the water flow streams from the step crest into the pool, most of the water energy dissipates. In addition to the height difference, other factors contribute to the energy dissipation in the step pool reaches. The present study examines the energy dissipation by determining its effective factors, including step height (H), step length (L), hydraulic radius $(\mathrm{R})$, sediment material diameter (d84), velocity in the step (V), etc. by field measurements in three reaches of mountain rivers. In the same vein, an equation is provided to estimate energy dissipation in the step pool reaches, by considering measurable effective parameters.
\end{abstract}

\section{Hosted file}

1400.08.10 energy - only text.doc available at https://authorea.com/users/447660/articles/ 546605-estimation-of-energy-dissipation-in-step-pool-reaches-of-mountain-river-a-fieldinvestigation 


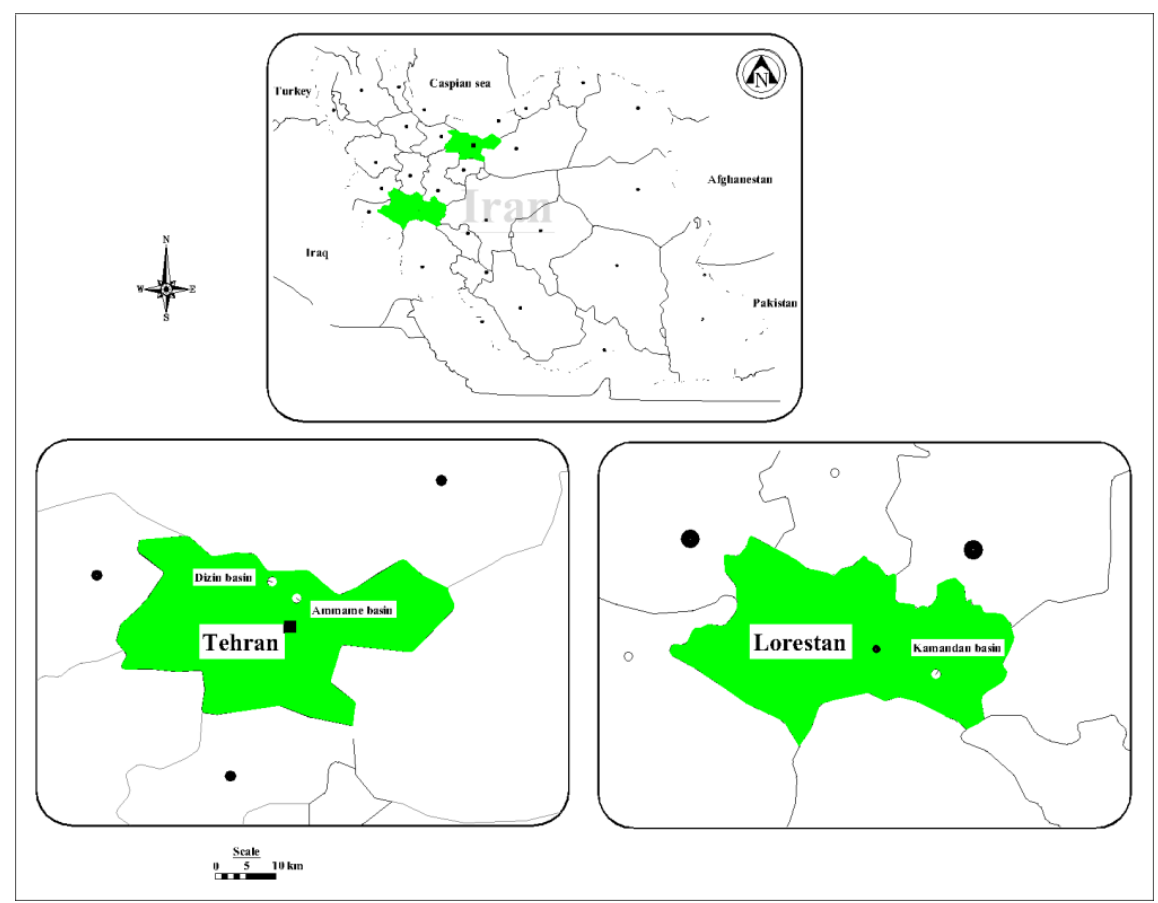




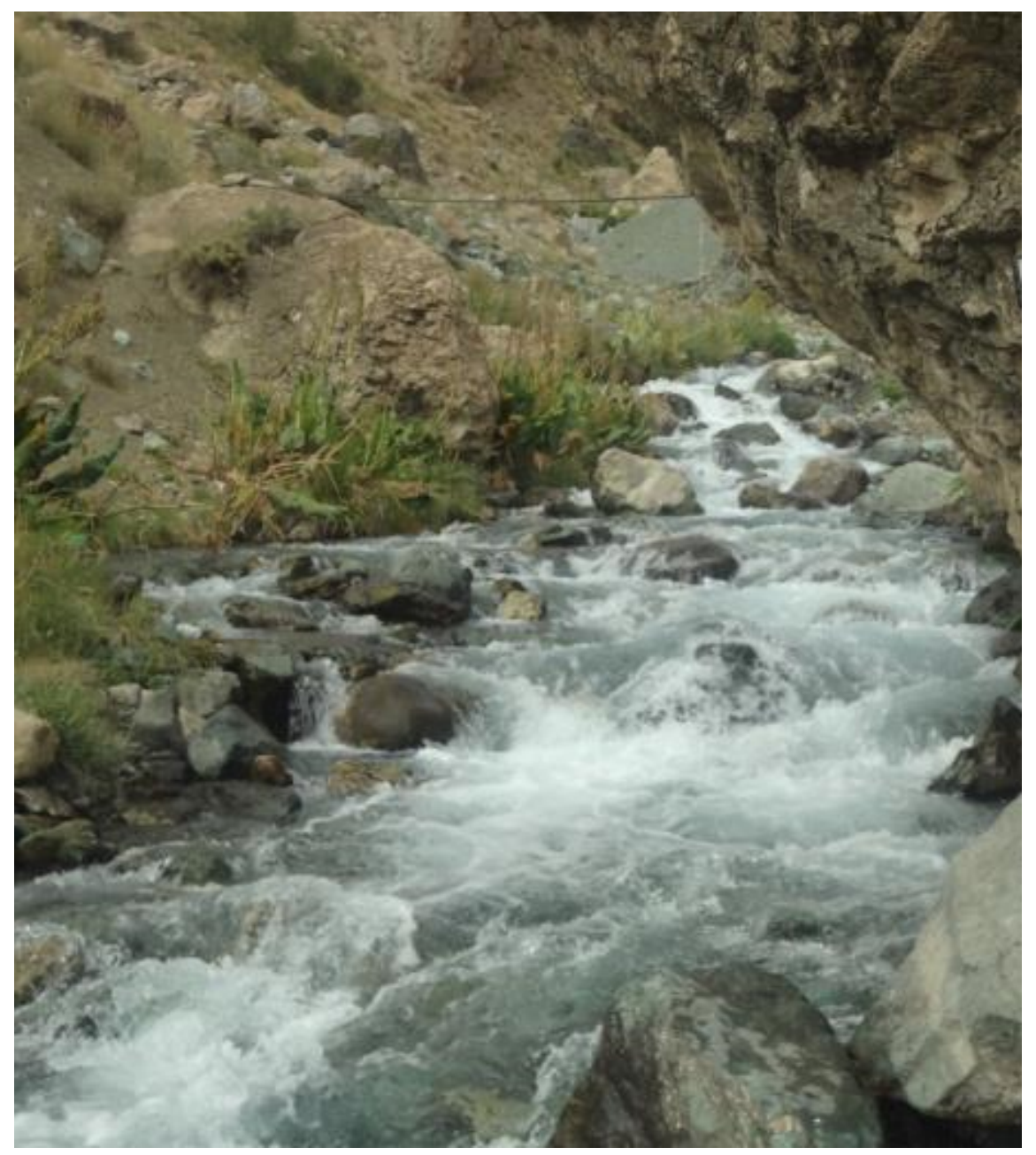



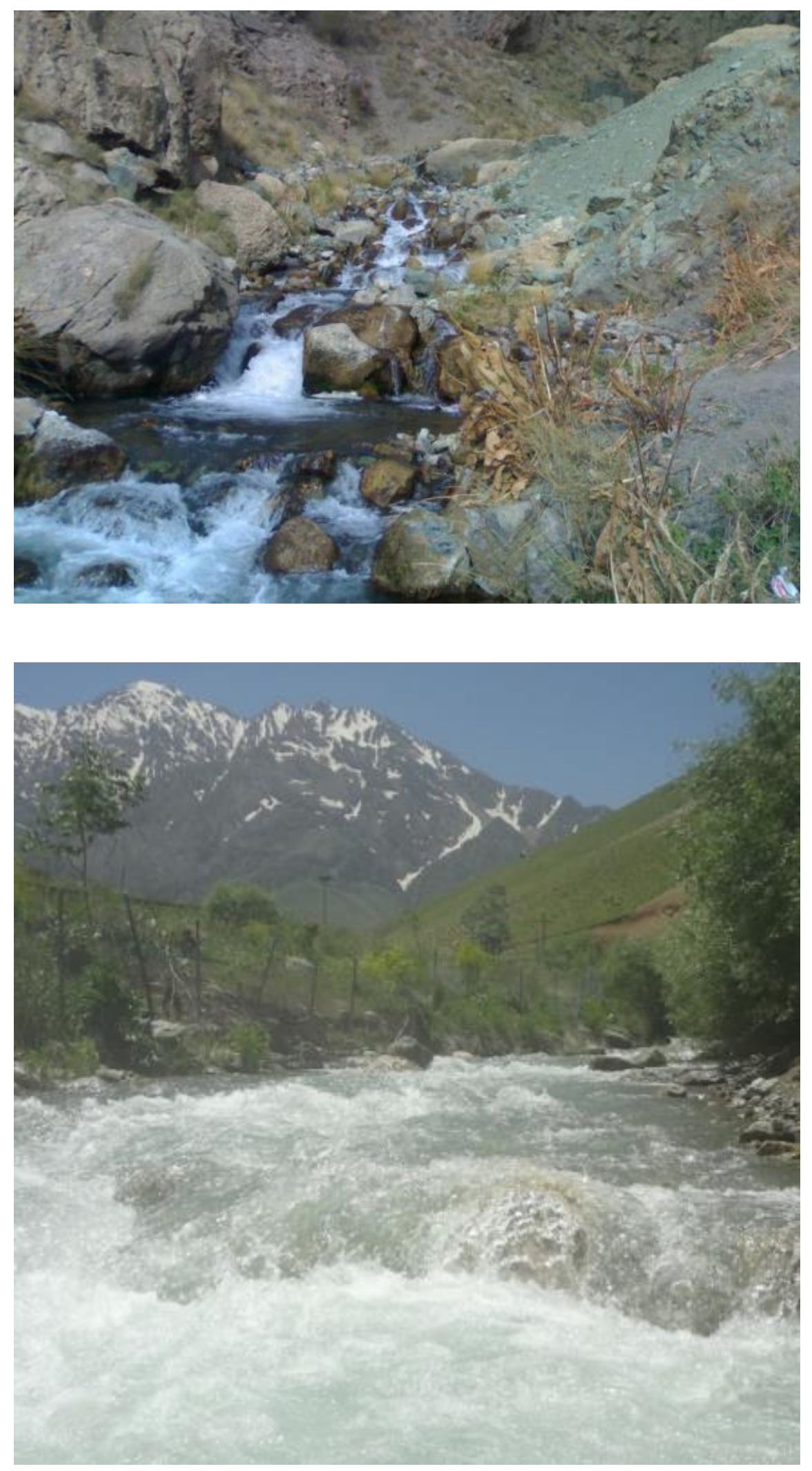


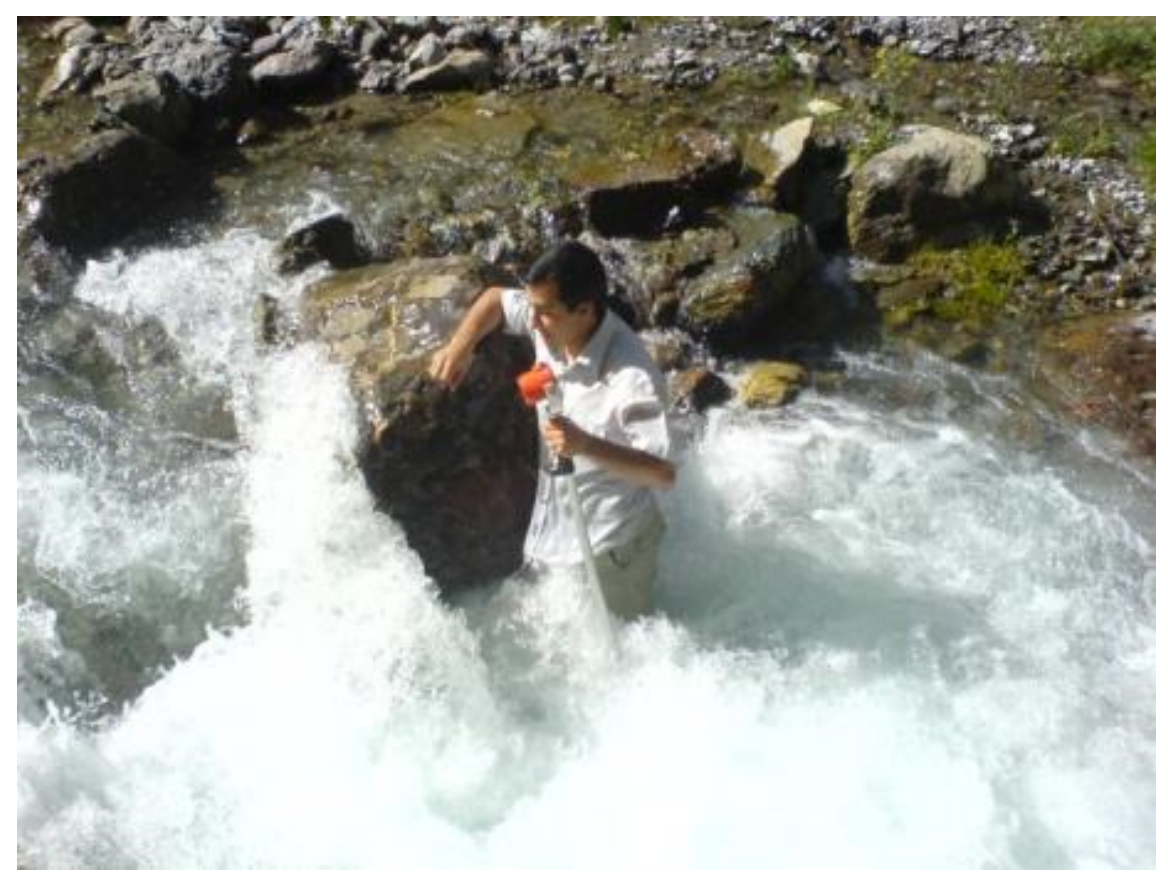

\section{Hosted file}

1400.08.10 energy -table.doc available at https://authorea.com/users/447660/articles/546605estimation-of-energy-dissipation-in-step-pool-reaches-of-mountain-river-a-fieldinvestigation

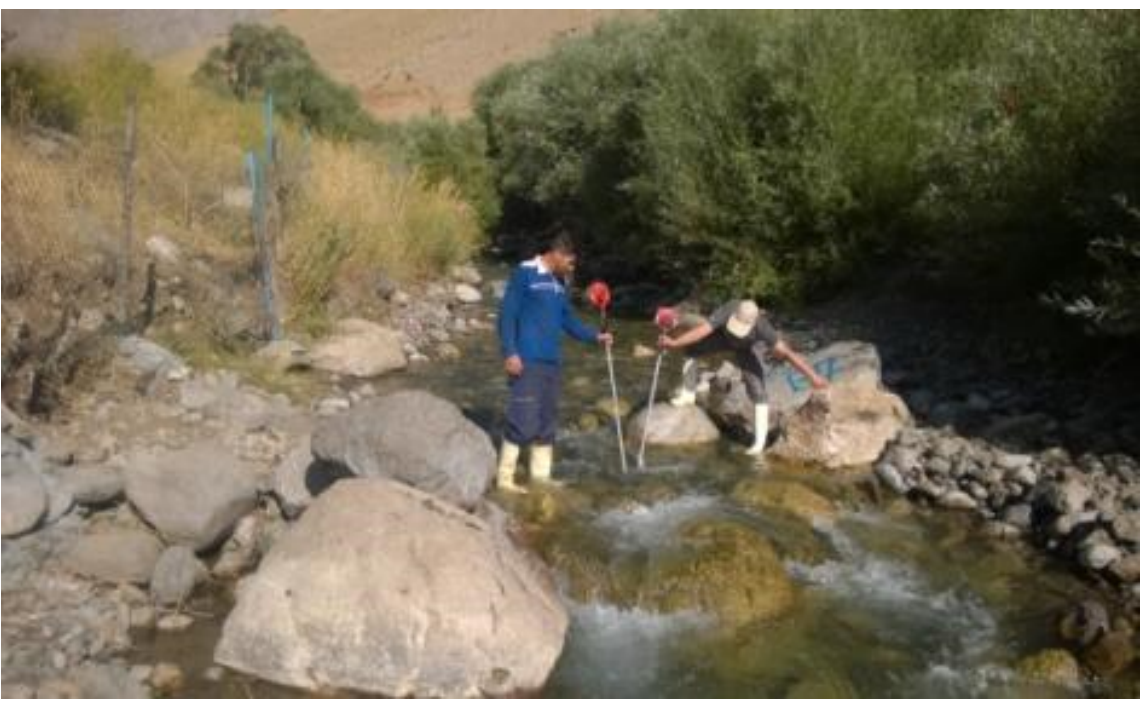



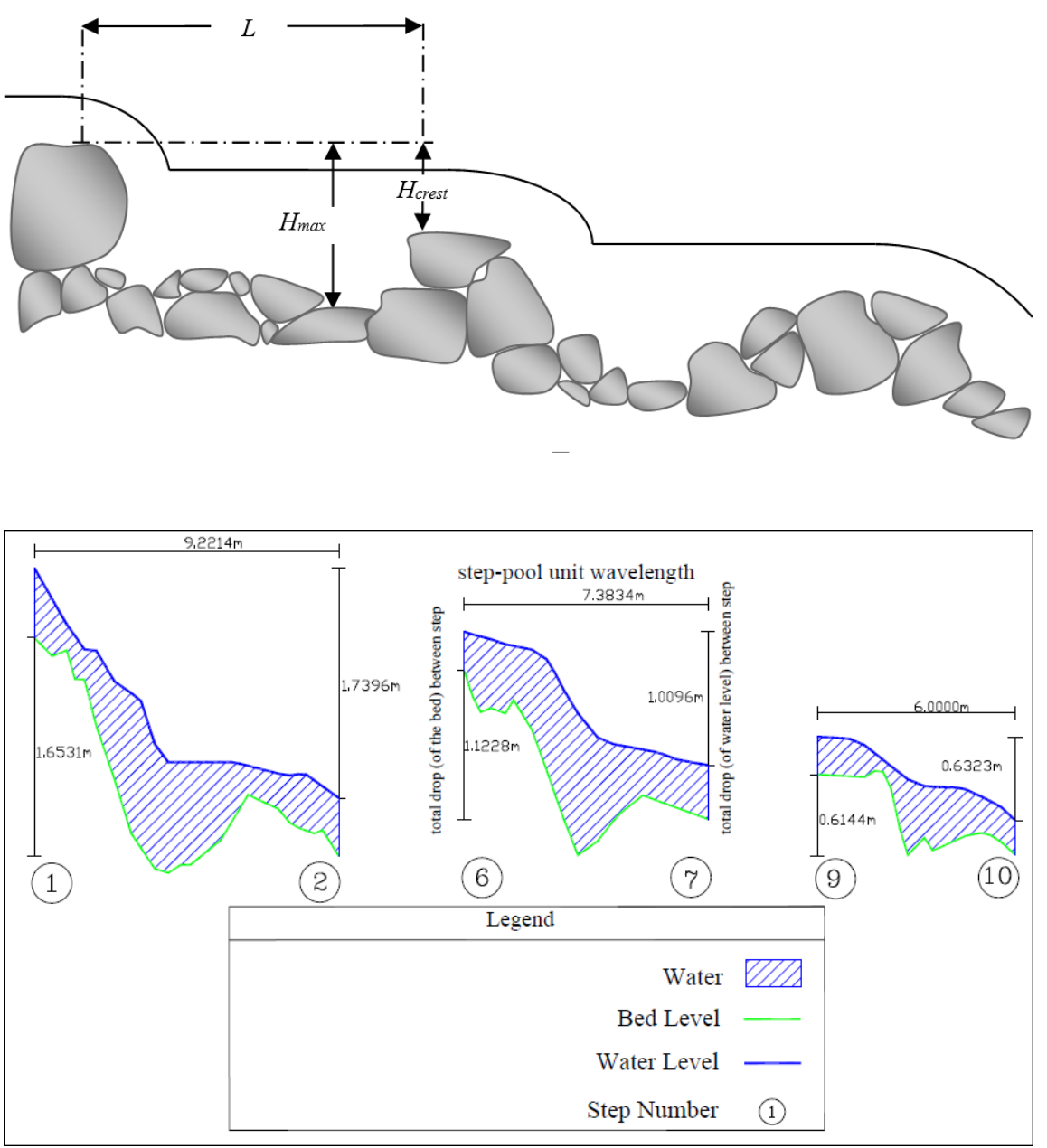

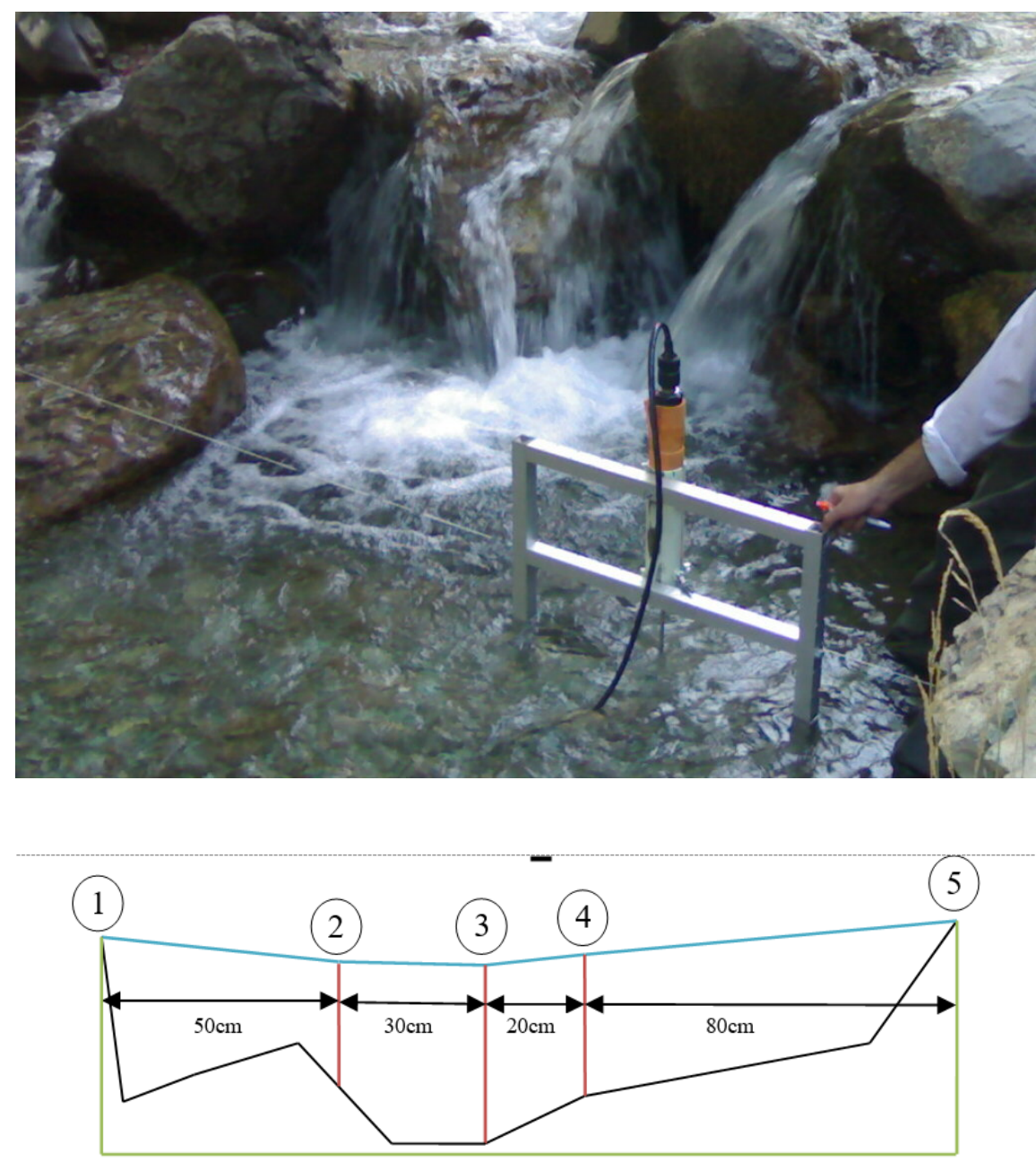

Bed profile

Water level

Vertical velocity measurement

Number of velocity measurement by ADV 

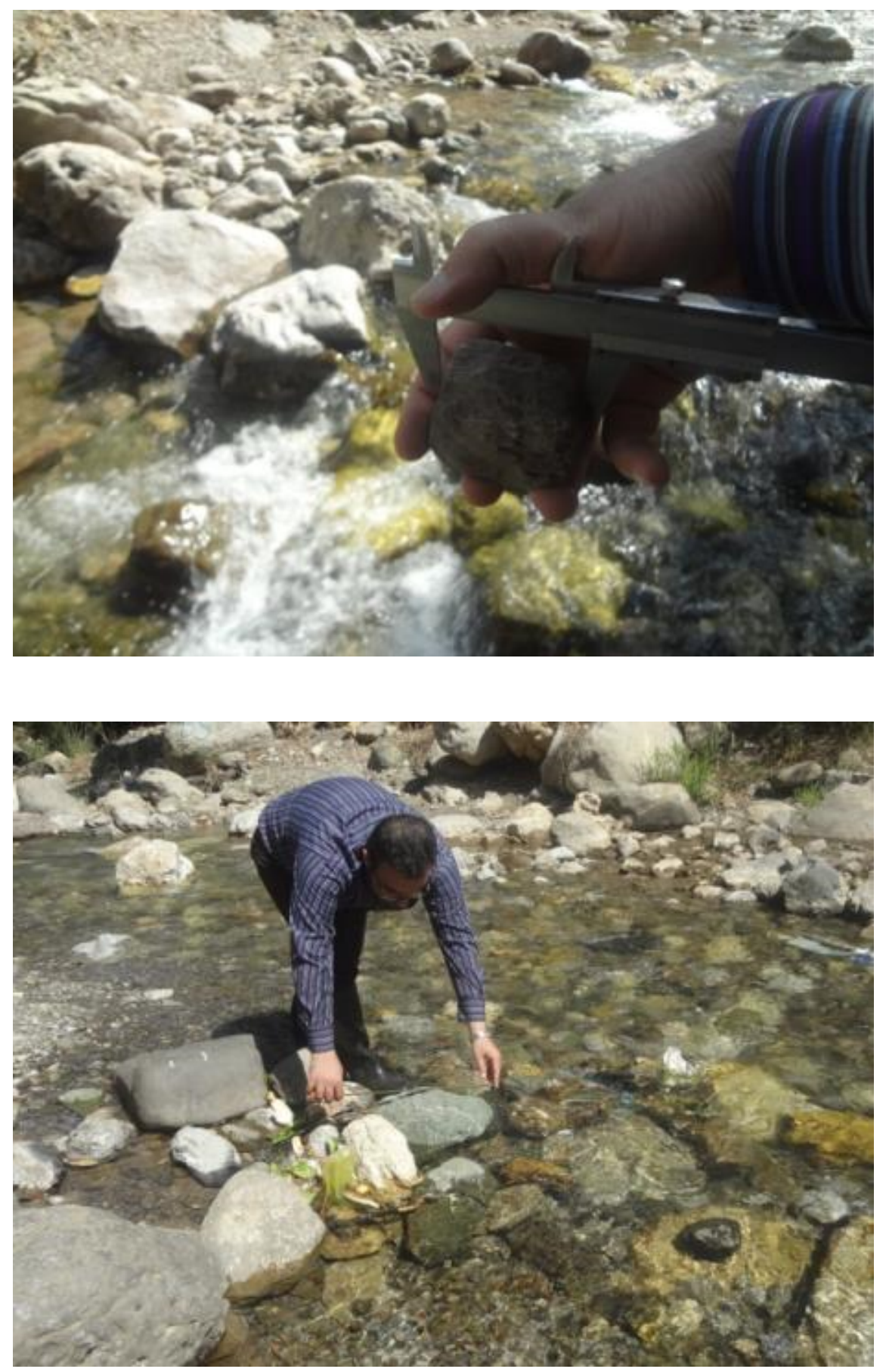

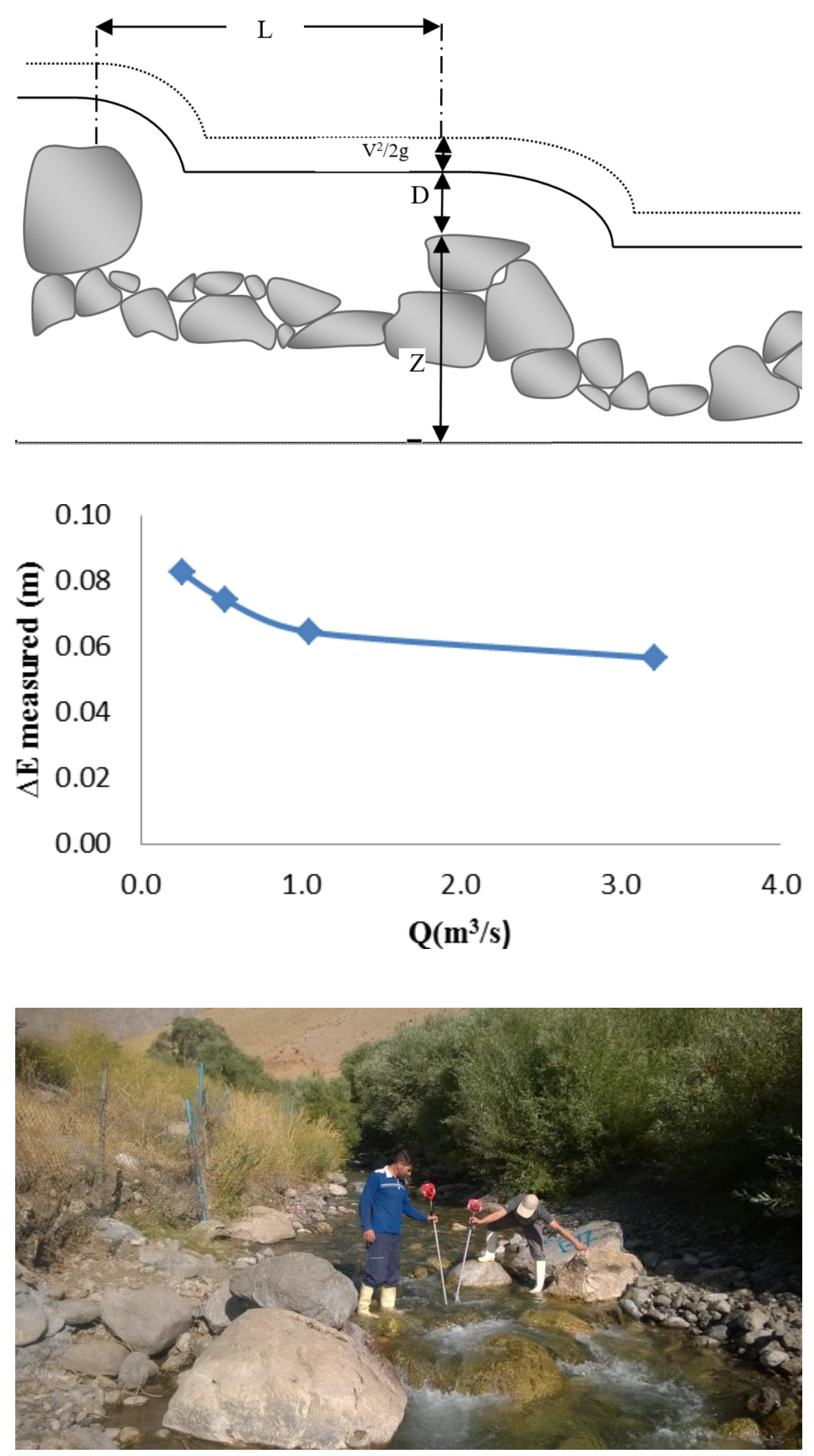